\title{
In situ Formation of a Sub-Nanometer Iridium Phosphide Catalyst from Supported Organometallic Species
}

\author{
Boris Sheludko, ${ }^{a, b}$ Evan C. Wegener, ${ }^{c}$ Gokhan Celik, ${ }^{c}$ A. Jeremy Kropf, ${ }^{c}$ Cristina F. Castro, ${ }^{b}$ \\ Massimiliano Delferro, ${ }^{c}$ Alan S. Goldman, ${ }^{a}$ David M. Kaphan, ${ }^{c, *}$ Fuat E. Celik ${ }^{b,+}$
}

\begin{abstract}
While several metal phosphides have attracted significant attention in the last several years due to their potential use as photocatalytic and hydrotreating catalysts, iridium phosphide has remained largely unexplored. In this work, silicasupported pincer-iridium species are thermolyzed, resulting in deconstruction of the tridentate ligand precursor and formation of a sub-nanometer iridium phosphide phase characterized by ${ }^{31} \mathrm{P}$ magic angle spinning nuclear magnetic resonance ( ${ }^{31} \mathrm{P}$-MAS-NMR), X-ray absorption spectroscopy (XAS), and high angle annular dark field scanning transmission electron microscopy (HAADF-STEM). The support material was found to play an active role in determining the product of the surface thermolysis, with the silica supported material generating phosphorus rich iridium phosphide nanoparticles. The resulting silica-supported iridium phosphide phase is explored as a thermocatalyst for non-oxidative butane dehydrogenation, achieving high initial reaction rates up to $900 \mathrm{~mol}_{\text {butenes }} \mathrm{mol}_{\text {catalyst }}{ }^{-1} \mathrm{hr}^{-1}$ and a terminal olefin selectivity of up to $70 \%$.
\end{abstract}

\section{Introduction}

As a class of materials, transition metal phosphides are unique in terms of both structure and reactivity. Such materials often have bulk physical and mechanical properties reminiscent of ceramics, while still exhibiting metal-like electronic characteristics, ${ }^{1}$ allowing access to interesting structures ${ }^{2}$ and reactivity not accessible via other materials such as metal nitrides or sulfides. Initially considered little more than "Chemist's Oddities", ${ }^{3}$ transition metal phosphides have garnered significant attention in the literature as active catalysts for, among other things, hydrotreating and the hydrogen evolution reaction (HER). ${ }^{14}{ }^{4}$ Nanostructured nickel phosphide $\left(\mathrm{Ni}_{2} \mathrm{P}\right)$, for instance, has been shown to exhibit Ptlike effectiveness for $\mathrm{HER}^{6}{ }^{6}$ and more recently, cobalt phosphide (CoP) has been explored as an efficient earthabundant alternative catalyst for the same process. ${ }^{7}$ While the majority of catalysis involving these species has primarily focused on these reactions, fledgling efforts have also begun to appear looking at the application of metal phosphides for other reactions such as methane dry reforming ${ }^{8}$ and NO dissociation/removal. ${ }^{9}$ Such materials are yet relatively unexplored and their study continues to reveal new and interesting applications in catalysis.

Key to optimizing the performance of these catalytic particles is the development of techniques for their precise synthesis, increasing the number of available active sites present in the catalytic system, which can be accomplished by

\footnotetext{
a. Department of Chemistry \& Chemical Biology, Rutgers, The State University of New Jersey, Piscataway, NJ 08854, United States

${ }^{b}$. Department of Chemical \& Biochemical Engineering, Rutgers, The State University of New Jersey, Piscataway, NJ 08854, United Statest

Chemical Sciences and Engineering Division, Argonne National Laboratory, Lemont, Illinois 60439, United States

* Tel.: +1 630252 8234. E-mail: kaphand@anl.gov

+Tel.: +1 848445 5558. E-mail: fuat.celik@rutgers.edu

Electronic Supplementary Information (ESI) available: Energy Dispersive X-ray (EDX) Analysis, ${ }^{31} \mathrm{P}$ MAS-NMR Spectra, X-ray Absorption Spectroscopy, Diffuse Reflectance Infrared Fourier-Transform Spectroscopy (DRIFTS).
}

decreasing the particle size. ${ }^{10}$ Synthetic strategies for nanoscale metal phosphide catalysts have thus been of critical importance in generating viable next-generation catalytic materials. ${ }^{11-20}$

While cobalt phosphide $7,17,18,21,22$ and rhodium phosphide ${ }^{23-29}$ catalysts have both been the subject of active study in recent literature, the catalytic properties ${ }^{30-33}$ of iridium phosphides have been less explored outside of structural and physical studies over the last half century, ${ }^{34-45}$ in part due to their difficult syntheses. ${ }^{46}$ This is in spite of the fact that, given the similarity often observed in the behavior of metal phosphides to their metal analogues, iridium-derived catalysts have often been found to be exceptional catalysts for reactions of great industrial value ${ }^{47,48}$ such as alkane dehydrogenation. ${ }^{49,50}$

In the course of our work with the silica-supported pinceriridium complex ${ }^{51} \mathbf{1} / \mathrm{SiO}_{2}\left[\left(\equiv \mathrm{SiO}^{-\mathrm{tBu} 4} \mathrm{POCOP}\right) \operatorname{Ir}(\mathrm{CO})\right]\left({ }^{\mathrm{tBu} 4} \mathrm{POCOP}\right.$ $\left.=\mathrm{k}^{3}-\mathrm{C}_{6} \mathrm{H}_{3}-2,6-\left(\mathrm{OP}(\mathrm{tBu})_{2}\right)_{2}\right)-$ prepared from molecular precursor complex 1 via the process shown in scheme 1, it was observed via Diffuse Reflectance Infrared Fourier-Transform Spectroscopy (DRIFTS) that loss of the pincer ligand occurs at approximately $420{ }^{\circ} \mathrm{C}$ to give an IR-silent species. ${ }^{52}$ The resulting decomposition product was found to be active toward alkane dehydrogenation and, in the course of characterization, was found to be a phosphorus-rich iridium phosphide nanophase.
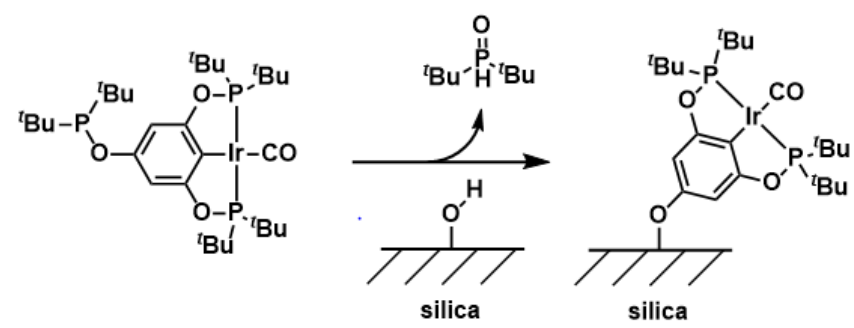

Scheme 1. Preparation of supported $\mathbf{1} / \mathrm{SiO}_{2}$ by exposure of 1 to silica. ${ }^{53}$ 
Iridium phosphide as a dehydrogenation catalyst may not be without precedent, in spite of its lack of recognition as such in the literature. It has been previously shown that the dehydrogenation activities of various, seemingly unrelated, iridium catalysts toward dehydrogenation at temperatures above $300{ }^{\circ} \mathrm{C}$ are strongly correlated to the number of equivalents of tertiary phosphine present in the system, whether loaded initially or pulsed while on stream. ${ }^{54-56}$ This was in spite of the fact that the phosphine ligands and/or additives used were observed to decompose, and even though these past experiments were performed in open, continuousflow systems which would allow for volatile phosphorus products to be removed from the catalyst bed. ${ }^{54,55}$ This is consistent with the phosphorus becoming "trapped" on the surface in an iridium phosphide phase, much like the one observed in this work.

The serendipitous precatalyst deconstruction observed here resulted in nanoparticles with an average size of $0.8-0.9$ $\mathrm{nm}$ in diameter that proved to be stable against agglomeration at temperatures up to $440{ }^{\circ} \mathrm{C}$, even under non-oxidative dehydrogenation conditions. While previous efforts toward the synthesis of small metal-phosphide nanoparticles have relied on the use of added detergents ${ }^{57}$ which would have to be removed prior to subsequent immobilization, the synthesis presented in this work was performed without any added solvents or additives and resulted in a well-dispersed silicasupported iridium phosphide phase. Here, this new material is characterized via scanning transmission electron microscopy as well as a number of spectroscopic techniques, and it is shown that not only is the synthesis of such small iridium-based phosphides feasible, but also that the resulting materials may have interesting thermocatalytic applications.

\section{Experimental Methods}

\section{Catalyst Preparation}

All chemical syntheses and material preparations were performed under an argon atmosphere unless otherwise noted. $\left[\left(p-t \mathrm{Bu}_{2} \mathrm{PO}_{-}{ }^{\mathrm{tBu} 4} \mathrm{POCOP}\right) \operatorname{Ir}(\mathrm{CO})\right] \quad(\mathbf{1})$ and $\left[\left(p-t \mathrm{Bu}_{2} \mathrm{PO}\right.\right.$ $\left.\left.{ }^{t B u 4} \mathrm{POCOP}\right) \operatorname{Ir}\left(\mathrm{C}_{2} \mathrm{H}_{4}\right)\right]$ (2) were synthesized and silica-supported catalyst $1 / \mathrm{SiO}_{2}$ and $2 / \mathrm{SiO}_{2}$ were prepared according to previously established procedures. ${ }^{51}$ Catalyst supported on hydrotalcite-derived $\mathrm{Mg}(\mathrm{Al}) \mathrm{O},{ }^{58} \mathbf{1 / M g}(\mathrm{Al}) \mathrm{O}$, was supported in an analogous fashion.

Calcination of support materials was carried out under dry air in a $6.4 \mathrm{~mm}$ outer diameter (OD) quartz tube reactor with an expanded section of $12.5 \mathrm{~mm}$ OD packed with quartz wool to hold the catalyst powder in place. After calcination, the powder was flushed with helium prior to being brought into an argon glovebox for further use. Supports were calcined to 550 ${ }^{\circ} \mathrm{C}$ with a ramp rate of $2{ }^{\circ} \mathrm{C} / \mathrm{min}$ and a hold of five hours at temperature.

\section{Gas-phase Continuous-flow Catalytic Data}

Plug-flow reactions were carried out in a $6.4 \mathrm{~mm}$ outer diameter (OD) quartz tube reactor with an expanded section of
$12.5 \mathrm{~mm}$ OD packed with quartz wool to hold the catalyst powder in place. The reactor was packed with supported catalyst under argon atmosphere, sealed with valves prior to connection to the gas-flow manifold, and connected under inert gas flow. The reactor was placed inside a resistively heated ceramic furnace with external temperature control, and the catalyst bed temperature was measured with a K-type thermocouple placed in direct contact with the catalyst bed. In a typical kinetic experiment in the quartz tube plug-flow reactor, $5 \mathrm{mg}$ of organometallic complex was supported on $150 \mathrm{mg}$ of support via incipient wetness impregnation, and all $155 \mathrm{mg}$ of the resulting material was loaded into the reactor.

Butane (Airgas, 99.99\%) was used as received. Helium (Praxair, 99.999\%) was passed through an on-stream oxygen and moisture trap. Reaction products were analyzed using an Agilent 7890B GC instrument equipped with a GS-GASPRO capillary column $(0.32 \mathrm{~mm} \times 60 \mathrm{~m})$ fitted with a splitter plate connected to a flame ionization detector and an Agilent 5977A mass spectrometer. Unless stated otherwise, all experiments were carried out at 1.27 atm total pressure by throttling a needle valve located downstream from the reactor. Gas flow rates reported were measured at room temperature and pressure.

Selectivity was calculated via:

$$
\begin{gathered}
S_{p}=x_{p} / \Sigma x_{p} \cdot 100 \% \\
\left(x_{p}=\text { mol fraction of product }\right)
\end{gathered}
$$

Carbon balance was calculated via:

$$
\text { C.B. }=\Sigma\left(x_{\mathrm{p}}{ }^{*} \text { C.N. }\right) / \Sigma\left(x_{\mathrm{r}}{ }^{*} \text { C.N. }\right) \cdot 100 \%
$$

$\left(x_{\mathrm{p}}=\right.$ mol fraction of product, $x_{\mathrm{r}}=$ mol fraction of reactant, C.N. $=$ carbon number)

\section{Sample Nomenclature}

Samples analyzed in this work are named according to the starting material used, the temperature to which this material was exposed, and the duration of exposure using the template

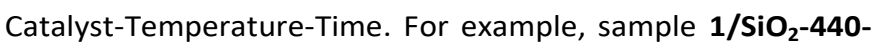
12 was obtained by exposing silica-supported 1 to $440{ }^{\circ} \mathrm{C}$ for 12 hours.

\section{Diffuse Reflectance Infrared Fourier Transform Spectroscopy (DRIFTS)}

DRIFTS measurements were performed using a Nicolet iS50 FTIR spectrometer equipped with a liquid nitrogen-cooled MCT/A detector and a Harrick HVC-DRM5 high temperature reaction chamber inside a Praying Mantis accessory. The reaction chamber temperature was calibrated with a wire thermocouple inserted into the catalyst bed under a closed dome through one of the inlets with no gas flow. The spectral resolution was set to $2 \mathrm{~cm}^{-1}$ and 64 scans were averaged for each spectrum shown. All spectra were collected using atmospheric suppression to eliminate signals arising from atmospheric water and carbon dioxide inside the instrument sample compartment but outside the reactor chamber. 
High-Angle Annular Dark-Field Scanning Transmission Electron Microscopy (HAADF-STEM)

The HAADF STEM images and EDS chemical mapping were collected at Electron Microscopy center at Argonne National Laboratory using FEI Talos Scanning Transmission Electron Microscope (80-300 kV). Samples in powder form were drydeposited on a TEM grid (Lacey carbon film on 400 mesh $\mathrm{Cu}$ grids - Ted Pella Inc.) without exposure to any solvent. The collection angle of HAADF images is chosen larger than 75 mrad to ensure the HAADF images are Z-contrast dominant.

\section{X-Ray Absorption Spectroscopy}

X-ray absorption spectra were collected on the insertion device and bending magnet beamlines of the Materials Research Collaborative Access Team (MR-CAT) at the Advanced Photon Source, Argonne National Laboratory. Measurements were performed at the $\mathrm{Ir} \mathrm{L}_{\text {III }}$ edge in transmission mode. Powder samples were pressed into a sixwelled, stainless steel holder forming self-supported wafers. The sample holder was placed in a quartz tube (1" O.D.) and sealed with two Ultra-Torr fittings equipped with Kapton windows and balls valves through which gases could be flowed. Samples were treated in a mixture of $1 \%$ butane/argon (Airgas) at the specified temperatures for 12 hours using a tube furnace. After treatment, the samples were cooled to room temperature, sealed with the ball vales, and then transferred to the beamline for measurements.

XAS data processing was performed using standard procedures and the Demeter software suite. ${ }^{59}$ Coordination parameters were determined from simultaneous fits in $\mathrm{R}$ space of the $k^{1}, k^{2}$, and $k^{3}$-weighted Fourier transformed EXAFS. Theoretical phase shift and back-scattering amplitudes were calculated using the FEFF software. ${ }^{60}$ An amplitude reduction factor $\left(\mathrm{S}_{0}{ }^{2}\right)$ of 0.76 was determined from fits of reference compounds with known coordination numbers $\left(\mathrm{IrCl}_{3}\right.$ and $\operatorname{Ir}(\mathrm{III})$ acetylacetonate) and was held constant in fits of the samples.

\section{Results and Discussion}

\section{Synthesis and TEM Characterization of Iridium Phosphide Nanoparticles}

Upon exposure to butane dehydrogenation conditions at 440 ${ }^{\circ} \mathrm{C}$ in a quartz tube reactor, pincer-iridium catalyst $1 / \mathrm{SiO}_{2}$ turned a grey-black color. The catalyst materials recovered from this treatment for 12 and 72 hours, $1 / \mathrm{SiO}_{\mathbf{2}}-\mathbf{4 4 0 - 1 2}$ and 1/SiO $\mathbf{S}_{\mathbf{2}} \mathbf{4 4 0 - 7 2}$ were observed via High-Angle Annular DarkField Scanning Transmission Electron Microscopy (HAADFSTEM) to be composed of small iridium-containing nanoparticles with an average size of $0.8 \pm 0.1$ and $0.9 \pm 0.1 \mathrm{~nm}$, respectively, present on the silica surface (Figure 1). Interestingly, prolonged thermolysis of the sample for longer periods of time did not seem to significantly impact their dispersity or size (Figure 1d).

From inductively coupled plasma - optical emission spectroscopy (ICP-OES), the percent by weight of iridium and phosphorus in $\mathbf{1} / \mathrm{SiO}_{\mathbf{2}}-\mathbf{4 4 0 - 1 2}$ was determined to be $0.67 \pm 0.05$ $w t \%$ and $0.42 \pm 0.05 w t \%$, respectively, corresponding to a $\mathrm{P} / \mathrm{lr}$ molar ratio of 3.1-3.9 (Robertson Microlit). Elemental analysis obtained using EDX (Figure S1) is consistent with this result, measuring a P/Ir ratio between 2 and 3 .

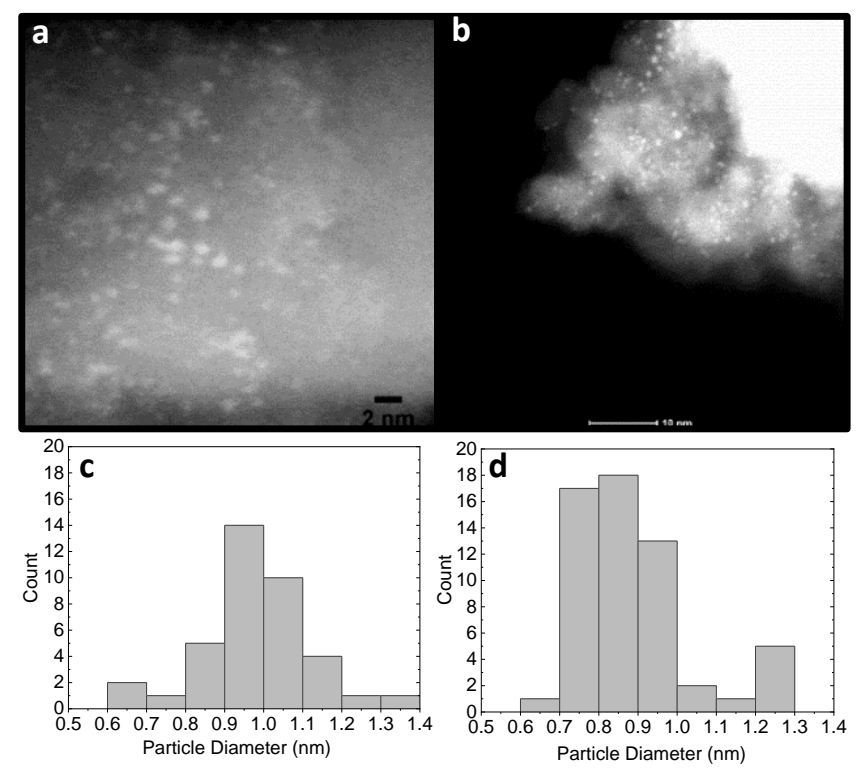

Figure 1. HAADF-STEM micrographs and histograms of iridiumcontaining species visualized in (a) $\mathbf{1} / \mathrm{SiO}_{\mathbf{2}}-\mathbf{4 4 0 - 1 2}$ and (b)

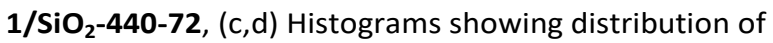
particle sizes in $(a, b)$, respectively.

\section{Spectroscopic Characterization of Iridium Phosphide Nanoparticles}

Based on the above results, it is clear that the conversion from $1 / \mathrm{SiO}_{2}$ to this new supported nanoparticle phase occurred at early reaction times (less than 12 hours), and particle size remained nearly unchanged upon extended exposure to reaction conditions. In order to investigate the structure of $\mathbf{1} / \mathrm{SiO}_{\mathbf{2}}-\mathbf{4 4 0}$ further, ${ }^{31} \mathrm{P}$ magic-angle spinning nuclear magnetic resonance ( ${ }^{31} \mathrm{P}$ MAS-NMR) was performed on a sample of $\mathbf{1} / \mathrm{SiO}_{\mathbf{2}}-\mathbf{4 4 0 - 3}$ (Figure S2a), resulting in a spectrum with three distinct features centered at ca. $0 \mathrm{ppm}$, corresponding to at least three distinct phosphorus chemical environments which may be attributed to oxidized phosphorus species such as silica-supported phosphates, ${ }^{61,}{ }^{62}$ phosphoric acid and phosphoric acid esters. ${ }^{63}$ Along with these, there were smaller, broad features at ca. $1420 \mathrm{ppm}$ and $420 \mathrm{ppm}$. Strong distortions in the baseline appeared to be unavoidable with any $\mathbf{1} / \mathrm{SiO}_{\mathbf{2}}-\mathbf{4 4 0 - X}$ sample, which has also been reported for ${ }^{31} \mathrm{P}$ MAS NMR spectroscopy of supported nickel phosphide species. $^{64}$

A correlation between the band gap structure of metal phosphides and their resultant phosphorus chemical shift(s) has previously been observed, ${ }^{65}$ with more metallic materials (those with narrower or nonexistent bandgaps) experiencing a Knight shift of greater magnitude downfield. Due to this effect, ${ }^{31} \mathrm{P}$ chemical shifts of some metal phosphides appear far downfield, e.g. $+3800 \mathrm{ppm}$ for the extreme case of CoP, instead of ca. +300 to $-300 \mathrm{ppm}$ more commonly encountered. 
Given this correlation to bandgap structure, a precise assignment of the phase in question based on ${ }^{31} \mathrm{P} N M R$ is difficult to make because, among other things, the size of the nanoparticles places them well below the continuum limit. Their proximity to the silica surface will also lead to electronic inhomogeneities across the nanoparticles as well.

To further characterize this iridium phosphide material, $X$ ray absorption spectroscopy (XAS) was performed on samples of $1 / \mathrm{SiO}_{2}$ treated at temperatures between $200-400{ }^{\circ} \mathrm{C}$ (Figure 2a). X-ray Absorption Near-Edge Structure (XANES) analysis indicated that up to $200{ }^{\circ} \mathrm{C}$, there was essentially no change in structure observed. At $300{ }^{\circ} \mathrm{C}$, there was a small
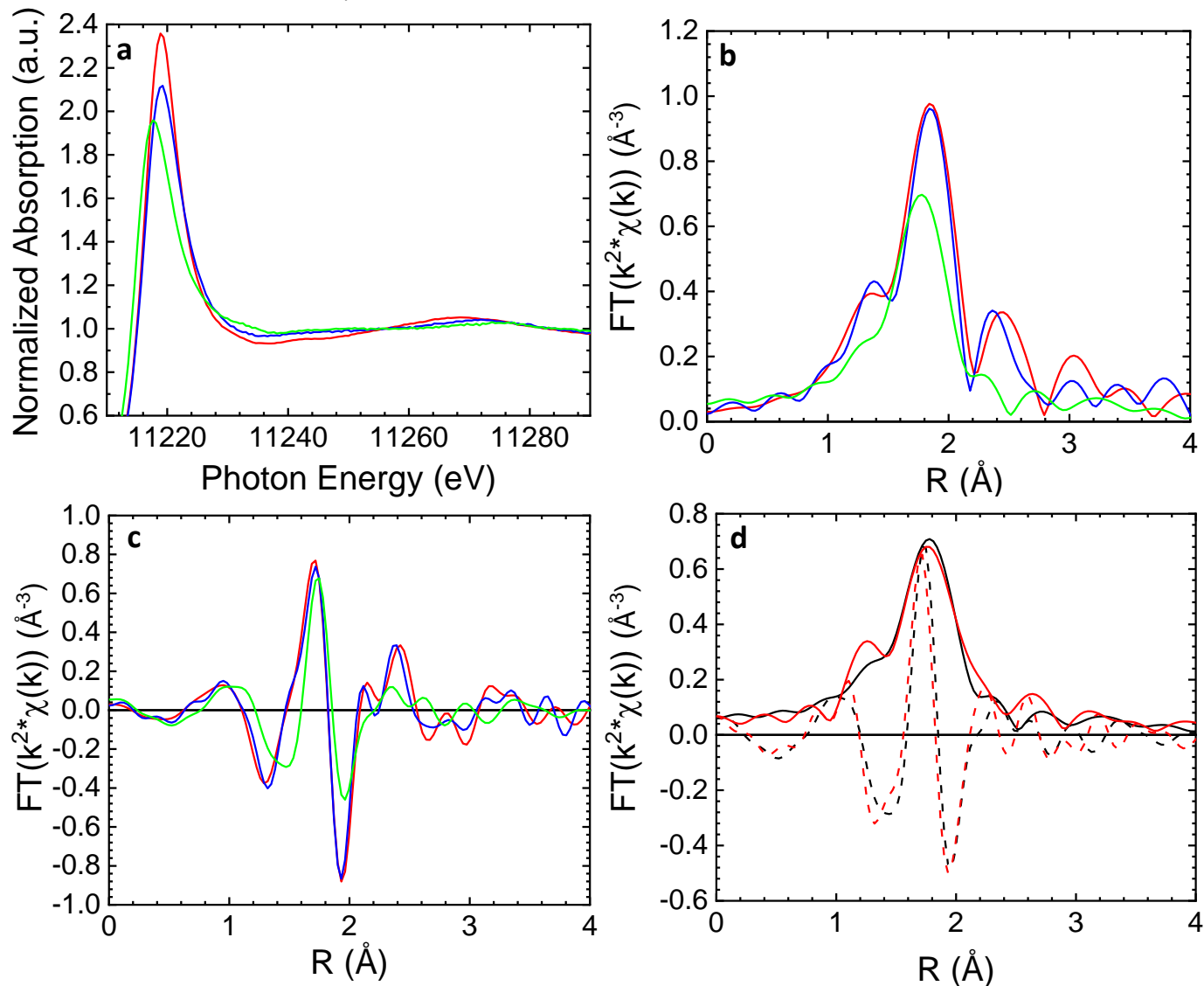

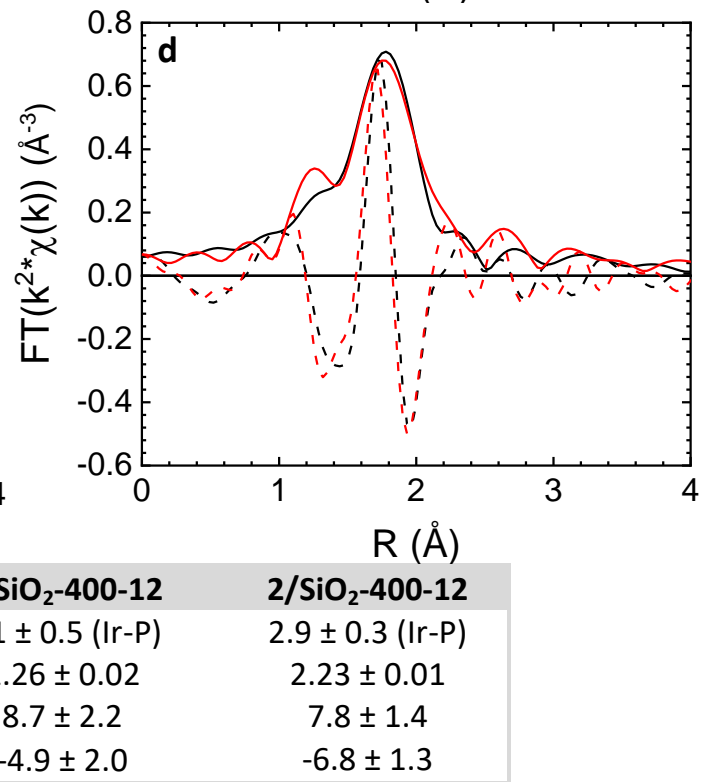

change observed as a feature between $11245-11260 \mathrm{eV}$, and by $400{ }^{\circ} \mathrm{C}$, the changes were significant enough to indicate that the majority of the iridium species on the surface had been converted to a new species associated with the small particles observed by HAADF-STEM.

Extended X-ray Absorption Fine Structure (EXAFS) analysis of the same samples (Figure 2b) showed that up to $300^{\circ} \mathrm{C}$, the iridium chemical environment remained largely stable, while at $400{ }^{\circ} \mathrm{C}$, the EXAFS region demonstrated loss of both pincer and CO ligands (Figure S3, S4), ${ }^{66,67}$ in agreement with DRIFTS spectroscopy that confirms loss of $\mathrm{CO}$ at this temperature. ${ }^{52}$

Figure 2. (a) XANES of $\mathbf{1} / \mathrm{SiO}_{2}$ after treatment in $1 \% \mathrm{C}_{4} \mathrm{H}_{10} / \mathrm{Ar}$ for $12 \mathrm{hr}$ at $200{ }^{\circ} \mathrm{C}(-), 300{ }^{\circ} \mathrm{C}(-)$, and $400{ }^{\circ} \mathrm{C}(-)$. (b) Magnitude of the FT-EXAFS of $\mathbf{1} / \mathrm{SiO}_{2}$ and after treatment in $\mathrm{C}_{4} \mathrm{H}_{10} / \mathrm{Ar}$ for $12 \mathrm{hr}$ at $200{ }^{\circ} \mathrm{C}(-), 300{ }^{\circ} \mathrm{C}(-)$, and $400{ }^{\circ} \mathrm{C}(-)$. (c) Real component of the $\mathrm{FT}$ EXAFS of $\mathbf{1 / \mathrm { SiO } _ { 2 }}$ and after treatment in $\mathrm{C}_{4} \mathrm{H}_{10} /$ Ar for $12 \mathrm{hr}$ at $200{ }^{\circ} \mathrm{C}(-), 300{ }^{\circ} \mathrm{C}(-)$, and $400{ }^{\circ} \mathrm{C}(-)$. (d) FT-EXAFS of $1 / \mathrm{SiO}_{2}$ after treatment in $\mathrm{C}_{4} \mathrm{H}_{10} / \mathrm{Ar}$ at $400{ }^{\circ} \mathrm{C}(-)$ and $500{ }^{\circ} \mathrm{C}(-)$ for 12 hours. All spectra were collected at room temperature. (e) Fitting parameters for $\mathbf{1} / \mathrm{SiO}_{2}-\mathbf{4 0 0 - 1 2}$ and $\mathbf{2} / \mathrm{SiO}_{2}-\mathbf{4 0 0 - 1 2}$.

The real component of the EXAFS Fourier transform (Figure 2c) allowed for observation of several other features which can be used to characterize the coordination sphere of the iridium center. The strongest feature, the negative peak present above $1.9 \AA$, primarily arises from Ir-P scattering (Figure $\mathrm{S} 3 \mathrm{~b}$ ) and may be used to determine the presence of phosphorus bound to iridium. The identical features at this distance in samples heated up to $300{ }^{\circ} \mathrm{C}$ were characteristic of Ir-P scattering arising from the bound $\left({ }^{\mathrm{tB} 4} \mathrm{P}\right.$ POCOP) ligand, while a significant change in the feature at roughly the same location at $400{ }^{\circ} \mathrm{C}$ suggested the formation of a novel coordination environment, with scattering still dominated by phosphorus atoms in the first shell coordination sphere. The points at which the function crosses the $\mathrm{X}$-axis also shifted to higher 
distances in going from 300 to $400{ }^{\circ} \mathrm{C}$, consistent with a significant structural change, including an elongation of the Ir$\mathrm{P}$ bond length. Important to note is the fact that there was no Ir-Ir scattering component detected between $2-3 \AA$, indicating that the major species was not composed of metallic iridium. The presence of iridium-phosphorus scattering in

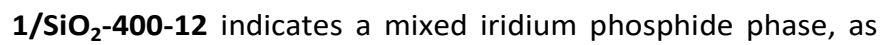
opposed to, for example, the presence of two separate types of nanoparticles on the surface. The final fit obtained for $\mathbf{1} / \mathrm{SiO}_{\mathbf{2}}-\mathbf{4 0 0 - 1 2}$ was consistent with three phosphorus atoms bound to iridium (Figure 2e).

Heating the starting material $\mathbf{1} / \mathbf{S i O}_{\mathbf{2}}$ further, to $500{ }^{\circ} \mathrm{C}$, for 12 hours $\left(1 / \mathrm{SiO}_{2}-\mathbf{5 0 0 - 1 2}\right)$ resulted in a change in the FT-EXAFS spectrum between 2 and $3 \AA$ (Figure $2 d$ ) consistent with the appearance in Ir-Ir scattering arising due to phosphorus loss at higher temperatures and production of a more metal rich iridium phosphide phase.

It was also found that when the starting pincer-iridium species used was ethylene complex $\mathbf{2} / \mathbf{S i O}_{2}$, thermolysis under butane at $400{ }^{\circ} \mathrm{C}$ resulted in EXAFS spectra consistent with a chemical environment identical to that observed when starting with $\mathbf{1} / \mathrm{SiO}_{2}-\mathbf{4 0 0 - 1 2}$ (Figure $2 \mathrm{e}$ ), indicating that the identity of the precatalyst L-type ligand is inconsequential to the final iridium phosphide phase formed. Minor differences in the fit are likely due to the presence of additional surface species arising from low temperature decomposition of $\mathbf{2} / \mathrm{SiO}_{2}{ }^{52}$

XANES analysis of samples obtained from thermolysis under either helium or butane also indicated that the specific gas under which the thermolysis was carried out was inconsequential to the final iridium chemical environment (Figure S5). This suggests that the mechanism involved with deconstruction of pincer ligand and either subsequent or concurrent formation of the iridium phosphide phase does not depend on the gas phase composition, and in particular does not require the presence of either alkane or hydrogen (which arises from dehydrogenation).

\section{Effect of Support on Final Iridium Environment}

In order to determine what, if any, role the support plays in generation of this supported iridium phosphide phase, a sample of 1 supported on $\mathrm{Mg}(\mathrm{Al}) \mathrm{O}$ and aged for three hours at

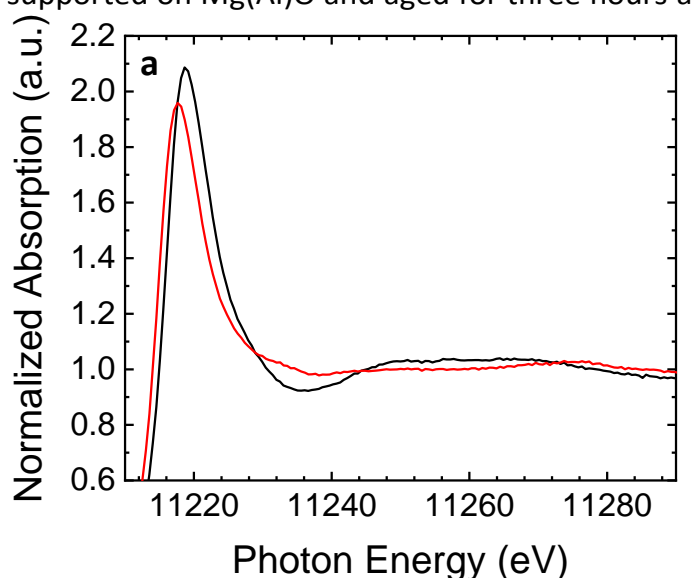

$440{ }^{\circ} \mathrm{C}$ under helium $(\mathbf{1} / \mathbf{M g}(\mathbf{A l}) \mathbf{0}-\mathbf{4 4 0})$ was analyzed via ${ }^{31} \mathrm{P}$ MAS-NMR (Figure S2b). While the chemical shifts of the phosphorus signals present at $0 \mathrm{ppm}$ were similar (and were thus also assigned to various molecular oxidized phosphorus species), no baseline distortion was observed, and no signals were observed downfield, inconsistent with the presence of an iridium phosphide phase.

EXAFS analysis of $\mathbf{1 / M g ( A I ) O}$ exposed to high temperatures (Figure S6) revealed a composition different from $1 / \mathrm{SiO}_{2}-\mathbf{4 0 0}$. Fitting parameters for $\mathbf{1 / M g ( A l ) O - 5 0 0 ~ ( F i g u r e ~ S 6 e ) ~}$ demonstrated an Ir-Ir coordination number of ca. 5, consistent with a metallic iridium phase not observed on silica. An Ir-P coordination number of 1 was also calculated, and these results indicate either a mixture of metallic iridium nanoparticles ${ }^{68}$ with an iridium phosphide phase, or a metal rich iridium phosphide phase, as opposed to the (relatively iridium-poor) iridium phosphide phase observed on silica.

This difference in decomposition products likely arises from a difference in the surface chemical environment, and the different interaction of the pincer-iridium complex therewith. This difference in surface interactions was also observed when comparing diffuse reflectance infrared Fourier-transform spectroscopic (DRIFTS) characterization of $\mathbf{1 / M g}(\mathrm{Al}) \mathrm{O}$ (Figure S7) and $1 / \mathrm{SiO}_{2}$ at $200{ }^{\circ} \mathrm{C}^{52} \mathbf{1 / M g ( A l ) O}$ showed a feature at higher wavenumbers corresponding to strong interaction of the iridium center with the surface which was absent in $1 / \mathrm{SiO}_{2}{ }^{52}$ In addition, multiple features in the spectrum for $\mathbf{1} / \mathbf{M g}(\mathbf{A l}) \mathbf{O}$ were assigned to decomposed iridium-containing materials. $^{69}$

Comparison of the XAS of $1 / \mathrm{SiO}_{\mathbf{2}}-\mathbf{4 0 0 - 1 2}$ and $\mathbf{1 / M g ( A I ) O -}$ 400-12 (Figure 3) revealed large differences in the XANES region as evidenced by the shift in white line position to lower energy accompanied by a decrease in intensity, as well as large differences in the features of the post-edge region between 11230-11240 eV. Differences in the EXAFS region were also observed, primarily due to the appearance of Ir-Ir scattering present in $\mathbf{1 / M g}(\mathbf{A l}) \mathbf{0}-\mathbf{4 0 0}-\mathbf{1 2}$. This demonstrates a fundamental importance of the nature of the support in determining the nature of the final iridium species present at high temperature.

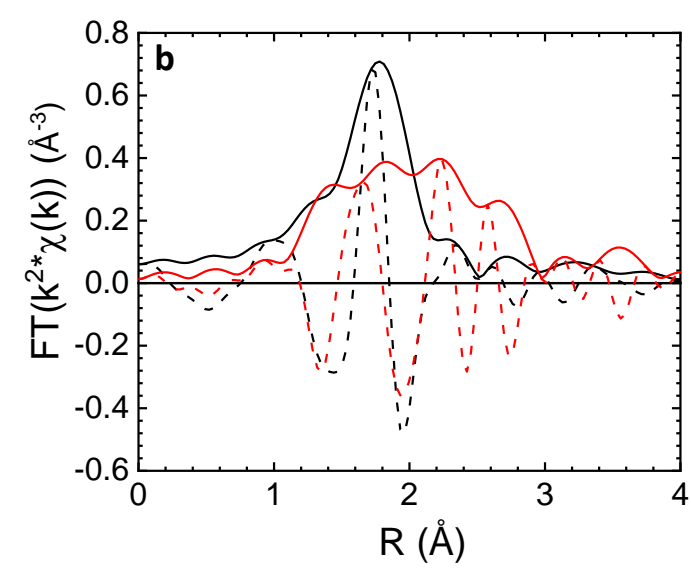

Figure 3. (a) XANES of $1 / \mathrm{SiO}_{2}-\mathbf{4 0 0 - 1 2}(-)$ and $1 / \mathrm{Mg}(\mathrm{Al}) 0-400-12(-)$ and (b) EXAFS of $1 / \mathrm{SiO}_{2}-\mathbf{4 0 0 - 1 2}(-)$ and $1 / \mathrm{Mg}(\mathrm{Al}) 0-400-12(-)$. 
Catalytic Properties of Silica-Supported Iridium Phosphide Nanoparticles

Flowing butane over a sample of $1 / \mathrm{SiO}_{2}$ at $440{ }^{\circ} \mathrm{C}$ in a quartz tube reactor following a temperature ramp up to this temperature under helium allowed for the analysis of reaction kinetics using in situ generated iridium nanoparticles. Results indicated an initial rate of butane dehydrogenation of ca. 900

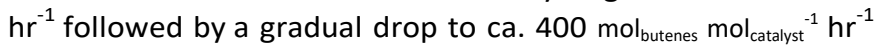
over the course of ca. 15 hours at $440{ }^{\circ} \mathrm{C}$ (Figure 4a). The fraction of terminal olefin product in this reaction was ca. $25 \%$, independent of time on stream, a value that corresponds to chemical equilibrium. The loss of activity is not a result of further, slow decomposition of starting $1 / \mathrm{SiO}_{2}$ as decomposition of the pincer-ligated species was complete by $440{ }^{\circ} \mathrm{C}$ as evidenced by loss of iridium carbonyl signals via DRIFTS, ${ }^{52}$ and confirmed by ex situ ${ }^{31} \mathrm{P}$ MAS-NMR. ${ }^{51}$ The cause of the slow deactivation is not well understood, but is unlikely to arise from changes in the nanoparticles, since particle size and XAS spectra were unchanged in this time interval. Instead, it is possible that coke formation takes place on the surface when hydrocarbon is present. Trace cracking products including $\mathrm{C}_{1}-\mathrm{C}_{3}$ hydrocarbons were also observed. This is also consistent with an observed carbon balance of ca. $92-95 \%$ at early reaction times, gradually increasing to $100 \%$ as the catalyst is deactivated and coking slows.

In contrast, the maximum observed rate under acceptorless dehydrogenation conditions with $\mathbf{1} / \mathbf{M g}(\mathbf{A l}) \mathbf{0}-\mathbf{4 4 0}$ was ca. $40 \mathrm{~mol}_{\text {butenes }} \mathrm{mol}_{\text {catalyst }}{ }^{-1} \mathrm{hr}^{-1}$ at $440{ }^{\circ} \mathrm{C}$ (Figure $4 \mathrm{~b}$ ), far lower than initial rates achieved with silica-supported species. This indicates that the iridium phosphide catalyst supported on silica was more active than the metallic particles generated on $\mathrm{Mg}$ (Al)O. Indeed, even at temperatures between $200-440{ }^{\circ} \mathrm{C}$, $1 / \mathbf{M g}$ (Al)O was observed to lose activity indicating that decomposition was taking place.

Transfer dehydrogenation was also performed with $\mathbf{1} / \mathrm{SiO}_{\mathbf{2}}-$ $\mathbf{4 4 0}$ using propene as a sacrificial hydrogen acceptor (Figure $4 \mathrm{c})$, and it was observed that while rates were significantly inhibited in comparison to the acceptorless case, the apparent selectivity approached ca. 70\% for the terminal olefin, 1butene. To our knowledge, pincer-iridium complexes have been reported to be the most regioselective catalysts for the formation of terminal olefins by dehydrogenation of $n$-alkanes in both homogeneous and heterogeneous systems. In solution, pincer-iridium complexes achieved regioselectivities up to ca. $88 \%$ after 10 minutes at $240{ }^{\circ} \mathrm{C}^{70}$ We reported instantaneous regioselectivities of ca. $50 \%$ in continuous-flow gas-phase systems at $300{ }^{\circ} \mathrm{C}$ using supported pincer-iridium complexes identical to $1 / \mathrm{SiO}_{2}{ }^{71}$ While the reaction conditions are significantly different between these experiments, the $70 \%$ terminal regioselectivity reported here is the highest for a heterogeneous and non-molecular catalyst reported to date.

\section{Conclusions}

Herein is presented a facile method for the in situ synthesis of small nanoparticles of iridium phosphide through the controlled deconstruction of pincer-iridium precursors supported on silica that are stable at high temperature toward agglomeration. Their stability toward agglomeration at elevated temperature, and under the non-negligible partial pressure of hydrogen resulting from dehydrogenation under these conditions, is surprising and will be the subject of further study. The iridium phosphide nanophase generated was demonstrated to be effective for alkane dehydrogenation, in one system achieving selectivity of up to $70 \%$ for the terminal olefin. These results are in contrast to those often observed upon decomposition of organometallic species either in solution or on surfaces, which typically results in metallic nanoparticles. The generation of the iridium phosphide nanophase discussed herein opens up new avenues of research focusing on generating other analogous metal phosphide nanophases, exploring the effect of other supports on the final structure, as well as the exploration of various thermocatalytic applications of such materials.

\section{Conflicts of interest}

There are no conflicts to declare.

\section{Acknowledgements}

This material is based upon work supported by the National Science Foundation (CBET-1705746) and the Department of Energy Office of Science (DE-SC0020139). Work at Argonne National Laboratory was supported by the U.S. Department of Energy (DOE), Office of Basic Energy Sciences, Division of Chemical Sciences, Geosciences, and Biosciences, Catalysis Science Program, under Contract DE-AC02-06CH11357. This research used resources of the Advanced Photon Source, a U.S. Department of Energy (DOE) Office of Science User Facility operated for the DOE Office of Science by Argonne National Laboratory under Contract DE-AC02-06CH11357. MRCAT operations are supported by the Department of Energy and the MRCAT member institutions.

The authors would like to thank Dr. Nagarajan Murali for help with collecting and interpreting ${ }^{31} \mathrm{P}$ MAS-NMR spectra, and Corey E. Frank for several informative, insightful discussions regarding the subject matter. 

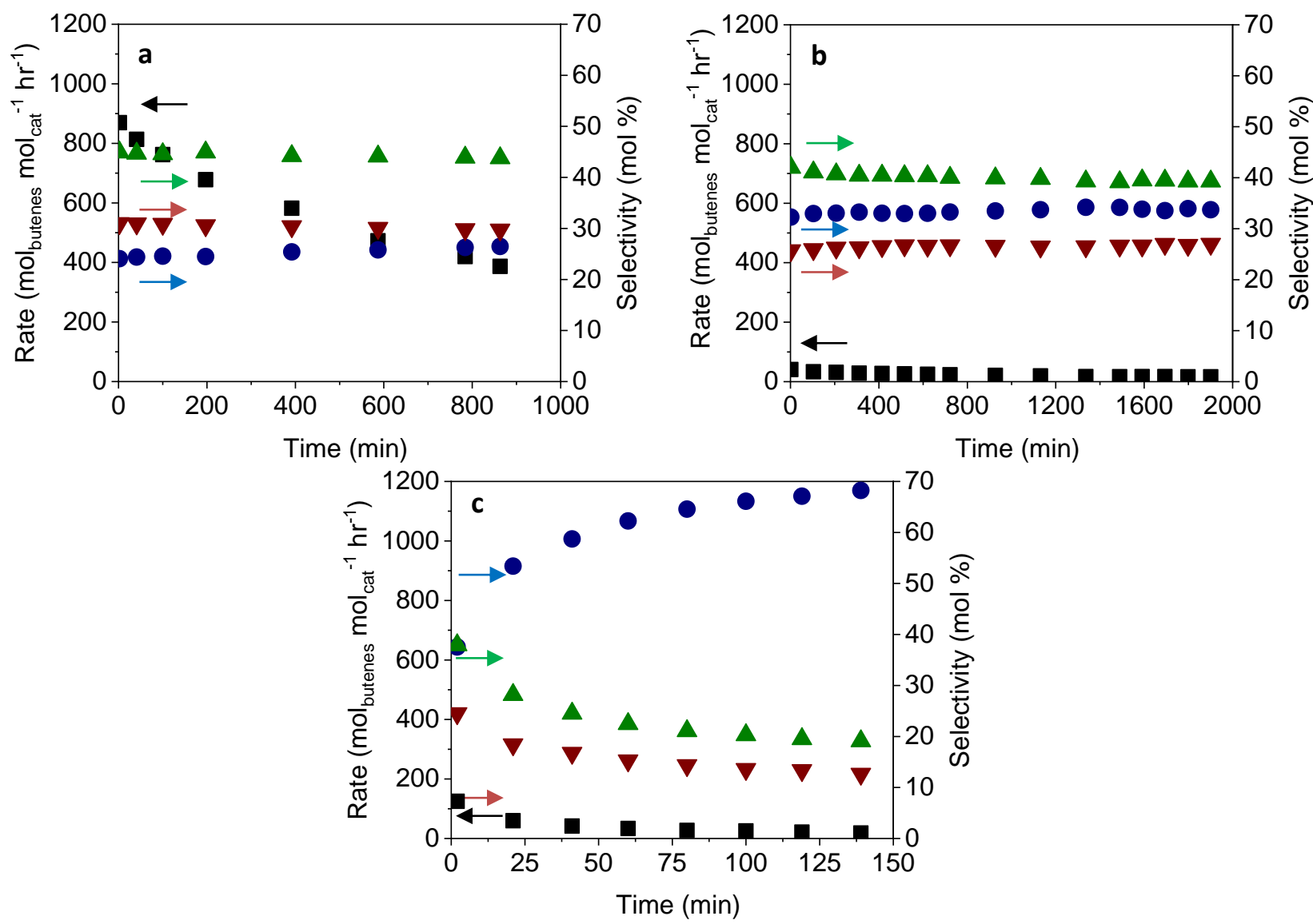

Figure 4. Measured (a and $\mathbf{b}$ ) acceptorless and (c) transfer butane-propylene dehydrogenation rates and selectivities of a sample

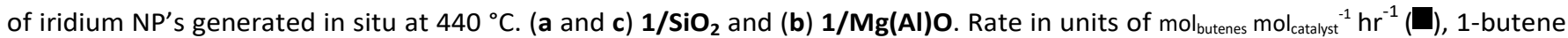
$(\mathbf{O})$, trans-2-butene $(\Delta)$, cis-2-butene $(\nabla)$. $P_{\text {butane }}=0.32 \mathrm{~atm}, P_{\text {total }}=1.28 \mathrm{~atm}(\mathrm{a}) n_{\text {cat }}=6.4 \mu \mathrm{mol}, \dot{V}_{\text {total }}=80 \mathrm{~mL} \mathrm{~min}{ }^{-1}, \tau=8 \times 10^{-5}$ mol $\min ^{-1} \mathrm{~L}^{-1}, P_{\mathrm{He}}=0.96 \mathrm{~atm}$. (b) $n_{\text {cat }}=1.3 \mu \mathrm{mol}, \dot{V}_{\text {total }}=20 \mathrm{~mL} \mathrm{~min}^{-1}, \tau=6.4 \times 10^{-5} \mathrm{~mol} \mathrm{~min}^{-1} \mathrm{~L}^{-1}, P_{\mathrm{He}}=0.96 \mathrm{~atm}$. (c) $n_{\text {cat }}=2.6 \mu \mathrm{mol}$, $\dot{V}_{\text {total }}=80 \mathrm{~mL} \mathrm{~min}^{-1}, \tau=3.3 \times 10^{-5} \mathrm{~mol} \mathrm{~min}^{-1} \mathrm{~L}^{-1}, P_{\text {propylene }}=0.32 \mathrm{~atm}, P_{\mathrm{He}}=0.64 \mathrm{~atm}$.

\section{Notes and references}

1. S. T. Oyama, T. Gott, H. Zhao and Y.-K. Lee, Catalysis Today, 2009, 143, 94-107.

2. J.-H. Chen and K. H. Whitmire, Coord. Chem. Rev., 2018, 355, 271-327.

3. M. D. S. Carenco, C. Boissiere, C. Sanchez, N. Mezailles, in Molecules at Work, 2012, DOI: 10.1002/9783527645787.ch6, pp. 113-120.

4. J. Su, J. Zhou, L. Wang, C. Liu and Y. Chen, Science Bulletin, 2017, 62, 633-644.

5. Y. Bonita and J. C. Hicks, in Alternative Catalytic Materials: Carbides, Nitrides, Phosphides and Amorphous Boron Alloys, The Royal Society of Chemistry, 2018, DOI: 10.1039/9781788013222-00046, pp. 46-70.

6. E. J. Popczun, J. R. McKone, C. G. Read, A. J. Biacchi, A. M. Wiltrout, N. S. Lewis and R. E. Schaak, Journal of the American Chemical Society, 2013, 135, 9267-9270.

7. M. F. Delley, Z. Wu, M. E. Mundy, D. Ung, B. M. Cossairt, H. Wang and J. M. Mayer, Journal of the American Chemical Society, 2019, 141, 15390-15402.

8. Y. Cui, Q. Liu, Z. Yao, B. Dou, Y. Shi and Y. Sun, International Journal of Hydrogen Energy, 2019, 44, 11441-11447.
9. Z. Yao, Chemical and Biochemical Engineering Quarterly, 2016, 29, 505-510.

10. J. A. Schaidle, S. E. Habas, F. G. Baddour, C. A. Farberow, D. A. Ruddy, J. E. Hensley, R. L. Brutchey, N. Malmstadt and H. Robota, in Catalysis: Volume 29, The Royal Society of Chemistry, 2017, vol. 29, pp. 213-281.

11. Y. Shi and B. Zhang, Chemical Society Reviews, 2016, 45, 1529-1541.

12. A. E. Henkes, Y. Vasquez and R. E. Schaak, Journal of the American Chemical Society, 2007, 129, 1896-1897.

13. Z. Yao, M. Li, X. Wang, X. Qiao, J. Zhu, Y. Zhao, G. Wang, J. Yin and H. Wang, Dalton T, 2015, 44, 5503-5509.

14. D. Ahluwalia, A. Varshney, S. Kumar, A. Kumar, S. G. Warkar, N. Singh and P. Dubey, Inorganic and Nano-Metal Chemistry, 2020, DOI: 10.1080/24701556.2020.1728551, 1-6.

15. Y. Tan, D. Sun, H. Yu, T. Wu, B. Yang, Y. Gong, S. Yan, R. $\mathrm{Du}, \mathrm{Z}$. Chen, X. Xing, G. Mo, Q. Cai and Z. Wu, Journal of Alloys and Compounds, 2014, 605, 230-236.

16. D. Li, K. Senevirathne, L. Aquilina and S. L. Brock, Inorg. Chem., 2015, 54, 7968-7975.

17. M. Zuo, L. Pan, T. Sun, D. Zhao, Z. Wang and H. Geng, Materials \& Design, 2016, 90, 858-866.

18. P. Buchwalter, J. Rosé, B. Lebeau, O. Ersen, M. Girleanu, P. Rabu, P. Braunstein and J.-L. Paillaud, Journal of Nanoparticle Research, 2013, 15, 2132. 

Govindaraj, Dalton T, 2012, 41, 5089-5120.

20. S. Carenco, M. Demange, J. Shi, C. Boissière, C. Sanchez, P. Le Floch and N. Mézailles, Chemical Communications, 2010, 46, 5578-5580.

21. Y. Pan, Y. Lin, Y. Chen, Y. Liu and C. Liu, Journal of Materials Chemistry A, 2016, 4, 4745-4754.

22. S. Shanmugam, A. Sivanantham, M. Matsunaga, U. Simon and T. Osaka, Electrochimica Acta, 2019, 297, 749-754.

23. F. Yang, X. Bao, D. Gong, L. Su, G. Cheng, S. Chen and W. Luo, ChemElectroChem, 2019, 6, 1990-1995.

24. Z. Pu, I. S. Amiinu, D. He, M. Wang, G. Li and S. Mu, Nanoscale, 2018, 10, 12407-12412.

25. Y. Kanda, Y. Matsukura, A. Sawada, M. Sugioka and Y. Uemichi, Applied Catalysis A: General, 2016, 515, 25-31.

26. J. Kim, H. Kim and S. H. Ahn, ACS Sustainable Chemistry \& Engineering, 2019, 7, 14041-14050.

27. J. R. Hayes, R. H. Bowker, A. F. Gaudette, M. C. Smith, C. E. Moak, C. Y. Nam, T. K. Pratum and M. E. Bussell, Journal of Catalysis, 2010, 276, 249-258.

28. Y. Kanda and Y. Uemichi, Journal of the Japan Petroleum Institute, 2015, 58, 20-32.

29. Y. Kanda, T. Chiba, R. Aranai, T. Yasuzawa, R. Ueno, T. Toyao, K. Kato, Y. Obora, K.-i. Shimizu and Y. Uemichi, Chem. Lett., 2019, 48, 471-474.

30. Z. Pu, J. Zhao, I. S. Amiinu, W. Li, M. Wang, D. He and S. Mu, Energy \& Environmental Science, 2019, 12, 952-957.

31. Z. Pu, T. Liu, W. Zhao, X. Shi, Y. Liu, G. Zhang, W. Hu, S. Sun and S. Liao, ACS Applied Materials \& Interfaces, 2020, 12, 11737-11744.

32. J. Yu, X. Wu, H. Zhang, M. Ni, W. Zhou and Z. Shao, ACS Applied Energy Materials, 2019, 2, 2645-2653.

33. A. T. Landers, M. Fields, D. A. Torelli, J. Xiao, T. R. Hellstern, S. A. Francis, C. Tsai, J. Kibsgaard, N. S. Lewis, K. Chan, C. Hahn and T. F. Jaramillo, ACS Energy Letters, 2018, 3, 1450-1457.

34. X. Ma, D. Zhou, Y. Yan, J. Xu, S. Liu, Y. Wang, M. Cui, Y. Cheng, Y. Miao and Y. Liu, Physical Chemistry Chemical Physics, 2019, 21, 21262-21266.

35. X. Ma, X. Li, D. Zhou, J. Xu, W. Gao and Y. Liu, Journal of Alloys and Compounds, 2019, 791, 1257-1262.

36. Z. J. Liu, T. Song, X. W. Sun, Q. Ma, T. Wang and Y. Guo, Solid State Communications, 2017, 253, 19-23.

37. X.-W. Sun, N. Bioud, Z.-J. Fu, X.-P. Wei, T. Song and Z.-W. Li, Physics Letters A, 2016, 380, 3672-3677.

38. M. Yang, M.-C. Chan and A. S. C. Cheung, Chem. Phys. Lett., 2016, 652, 230-234.

39. P. Wang, Y. Wang, L. Wang, X. Zhang, X. Yu, J. Zhu, S. Wang, J. Qin, K. Leinenweber, H. Chen, D. He and Y. Zhao, Scientific Reports, 2016, 6, 21787.

40. B. Khan, H. A. R. Aliabad, Saifullah, S. Jalali-Asadabadi, I. Khan and I. Ahmad, Journal of Alloys and Compounds, 2015, 647, 364-369.

41. H. Luo, J. W. Krizan, L. Muechler, N. Haldolaarachchige, T. Klimczuk, W. Xie, M. K. Fuccillo, C. Felser and R. J. Cava, Nature Communications, 2015, 6, 6489.

42. C. M. Sweeney, K. L. Stamm and S. L. Brock, Journal of Alloys and Compounds, 2008, 448, 122-127.

43. K. Takegahara and H. Harima, Physica B: Condensed Matter, 2003, 328, 74-76.

44. S. Ohta and H. Onmayashiki, Physica B: Condensed Matter, 1998, 253, 193-202.
45.

46.

48.

49.

50.

51.

52.

of

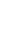

54.

55.

56.

57.

59.

R. Kaner, C. A. Castro, R. P. Gruska and A. Wold, Materials Research Bulletin, 1977, 12, 1143-1147.

C. J. Raub, W. H. Zachariasen, T. H. Geballe and B. T. Matthias, Journal of Physics and Chemistry of Solids, 1963, 24, 1093-1100.

K. I. Goldberg and A. S. Goldman, Accounts of Chemical Research, 2017, 50, 620-626.

J. J. H. B. Sattler, J. Ruiz-Martinez, E. Santillan-Jimenez and B. M. Weckhuysen, Chem. Rev., 2014, 114, 10613-10653.

Y. Ge, H. Jiang, R. Kato and P. Gummagatta, The Journal of Physical Chemistry A, 2016, 120, 9500-9508.

A. Kumar, T. M. Bhatti and A. S. Goldman, Chem. Rev., 2017, 117, 12357-12384.

B. Sheludko, M. T. Cunningham, A. S. Goldman and F. E. Celik, ACS Catalysis, 2018, 8, 7828-7841.

B. Sheludko, C. F. Castro, A. S. Goldman and F. E. Celik, Poison or Promoter? Investigating the Dual-Role of Carbon Monoxide in Pincer-Iridium-Based Alkane Dehydrogenation Systems via Operando Diffuse Reflectance Infrared Fourier Transform Spectroscopy, 2020, submitted manuscript. Preprint DOI: 10.26434/chemrxiv.12402590.v1.

B. C. Vicente, Z. Huang, M. Brookhart, A. S. Goldman and S. L. Scott, Dalton Trans, 2011, 40, 4268-4274.

H. G. Alt and I. K. Boehmer, Angew. Chem.-Int. Edit., 2008, 47, 2619-2621.

I. K. Boehmer and H. G. Alt, Journal of Organometallic Chemistry, 2009, 694, 1001-1010.

S. Taubmann and H. G. Alt, J. Mol. Catal. A-Chem., 2008, 287, 102-109.

S. E. Habas, F. G. Baddour, D. A. Ruddy, C. P. Nash, J. Wang, M. Pan, J. E. Hensley and J. A. Schaidle, Chemistry of Materials, 2015, 27, 7580-7592.

V. Galvita, G. Siddiqi, P. Sun and A. T. Bell, Journal of Catalysis, 2010, 271, 209-219.

60. J. J. Rehr, J. Mustre de Leon, S. I. Zabinsky and R. C. Albers, Journal of the American Chemical Society, 1991, 113, 5135-5140.

61. S. Liu, J. M. Tan, A. Gulec, N. M. Schweitzer, M. Delferro, L. D. Marks, P. C. Stair and T. J. Marks, ACS Catalysis, 2016, 6, 8380-8388.

62. S. Liu, J. M. Tan, A. Gulec, L. A. Crosby, T. L. Drake, N. M. Schweitzer, M. Delferro, L. D. Marks, T. J. Marks and P. C. Stair, Organometallics, 2017, 36, 818-828.

63. C. Weinberger, T. Heckel, P. Schnippering, M. Schmitz, A. Guo, W. Keil, H. C. Marsmann, C. Schmidt, M. Tiemann and R. Wilhelm, Nanomaterials (Basel), 2019, 9, 249.

64. C. Stinner, Z. Tang, M. Haouas, T. Weber and R. Prins, Journal of Catalysis, 2002, 208, 456-466.

65. E. Bekaert, J. Bernardi, S. Boyanov, L. Monconduit, M. L. Doublet and M. Ménétrier, The Journal of Physical Chemistry C, 2008, 112, 20481-20490.

66. M. Rimoldi, D. Fodor, J. A. van Bokhoven and A. Mezzetti, Catal. Sci. Technol., 2015, 5, 4575-4586.

67. D. B. Lao, A. C. E. Owens, D. M. Heinekey and K. I. Goldberg, ACS Catalysis, 2013, 3, 2391-2396.

68. J. Du, X. Sun, J. Chen and G. Jiang, The Journal of Physical Chemistry A, 2010, 114, 12825-12833.

69. G. B. McVicker, R. T. K. Baker, R. L. Garten and E. L. Kugler, Journal of Catalysis, 1980, 65, 207-220. 
70. A. Kumar, T. Zhou, T. J. Emge, O. Mironov, R. J. Saxton, K. Krogh-Jespersen and A. S. Goldman, J Am Chem Soc, 2015, 137, 9894-9911.

71. B. Sheludko, C. F. Castro, C. A. Khalap, T. J. Emge, A. S. Goldman and F. E. Celik, Regioselective Gas-Phase nButane Transfer Dehydrogenation via Silica-Supported Pincer-Iridium Complexes, 2020, submitted manuscript. Preprint DOI: 10.26434/chemrxiv.12885491 